\title{
CAPÍTULO 29: PRÉ-TRATAMENTO BIOLÓGICO E SACARIFICAÇÃO DA BIOMASSA DE FURCRAEA FOETIDA COMO POTENCIAL PARA PRODUÇÃO DE BIOETANOL DE SEGUNDA GERAÇÃO
}

\section{CHAPTER 29: BIOLOGICAL PRE-TREATMENT AND SACARIFICATION OF FURCRAEA FOETIDA BIOMASS AS A POTENCIAL FOR SECOND GENERATION BIOETHANOL PRODUCTION}

\author{
Giovanni Tombolato Gaeta ${ }^{1}$; Critina Giatti Marques de Souza ${ }^{2}$, Rosane Marina Peralta $^{3}$, Rafael \\ Castoldi $^{4}$
}

\begin{abstract}
Resumo
A produção de bioetanol vem se mostrando uma tendência mundial frente aos combustíveis fósseis. O processo de pré-tratamento com microrganismos da biomassa lignocelulósica aumenta a digestibilidade do material e possibilitar o processo de recuperação dos polissacarídeos. Dentre as biomassas vegetais, a Furcraea Foetida, uma Agavácea, muito utilizada na obtenção de fibras naturais, tem potencial desconhecido para obtenção de açucares fermentescíveis. Visando facilitar a sacarificação enzimática dos polissacarídeos e a produção de enzimas por estirpes de fungos do gênero Ganoderma, Pleurotus e Fusarium, foram realizadas a quantificação e caracterização de enzimas degradadoras de celulose e hemicelulose. A atividade de enzimas ligninolíticas por basidiomicetos, apresentou valores $20 \%$ maiores para o cultivo de Pleurotus, enquanto que a atividade de lacase no mesmo período, apresentou diferenças de $129 \%$ em cultivos de $P$. ostreatus. Cultivos de basidiomicetos apresentaram uma degradação entre $94 \%$ e $88 \%$ dos compostos fenólicos. O processo de sacarificação pelo pool enzimático Cellic-CTec2 gerou valores de 81,61 $\pm 8,43$ $\mu \mathrm{mol} / \mathrm{mL}$ de açucares redutores em meios pré-tratados por basidiomicetos, uma melhora de 66,3\%. Sacarificações realizadas sobre amostras pré-tratadas com Fusarium lateritium var. Majus, apresentaram uma menor liberação de açucares redutores, entre 28,27 $\pm 3,61$ $\mu \mathrm{mol} / \mathrm{mL}$ com aumento de $30,82 \%$.
\end{abstract}

Palavras-Chaves: Pré-tratamento; Bioetanol; Sacarificação; Furcraea foetida.

\begin{abstract}
The production of bioethano has shown to be a worldwide trend in relation to fóssil fuels. The pretratment process of lignocellulosic biomass with microorganisms increases the digestibility of the material and enables the processo of polysaccharide recovery. Among the plants biomass, Furcraea Foetida, an agavácea, widely used to obtaining natural fibers, has unknown potential for obtaining fermentable sugars. In order to facilitate the enzymatic saccharification of the polysaccharides and the production of enzymes by strains of fungi from the genus Ganoderma, Pleurotus and Fusarium, the quantification and characterization of cellulose and hemicellulose degrading enzymes were carried out. The activity of ligninolytic enzymes by basidiomycetes, showed $20 \%$ higher values for the cultivation of Pleurotus, while the lacase activity in the same period, showed differences of $129 \%$ in cultures of P. ostreatus. Basidiomycete cultures showed a degradation between $94 \%$ and $88 \%$ of the phenolic compounds.

\footnotetext{
${ }^{1}$ Graduado em Bioquímica pela Universidade Estadual de Maringá - giovannitgaeta@gmail.com

${ }^{4}$ Professor Doutor no Departamento de Bioquímica da Universidade Estadual de Maringá - $\underline{\text { rcastoldi@uem.br }}$
}

${ }^{2}$ Professora Doutora no Departamento de Bioquímica da Universidade Estadual de Maringá - cgmsouza@uem.br

${ }^{3}$ Professora Doutora no Departamento de Bioquímica da Universidade Estadual de Maringá - rmperalta@uem.br
\end{abstract}


The saccharification process by the Cellic-CTec2 enzymatic pool generated values of 81.61 $\pm 8.43 \mu \mathrm{mol} / \mathrm{mL}$ of reducing sugars in pre-treated media with basidiomycetes, an improvement of $66.3 \%$. Saccharifications performed on samples pretreated with Fusarium lateritium var. Majus, showed a lower release of reducing sugars, between $28.27 \pm 3.61$ $\mu \mathrm{mol} / \mathrm{mL}$ with an increase of $30.82 \%$.

Keywords: Pre-Treatment, Bioethanol, Saccharification, Furcraea Foetida

\section{Introdução}

\section{A produção de biocombustíveis}

O termo biomassa pode ser definido como qualquer matéria orgânica produzida a partir da fotossíntese ou até mesmo qualquer material derivado dos seres vivos. A biomassa vegetal, principalmente, tem um potencial biotecnológico na produção de açúcares fermentáveis, que podem ser utilizados para produção de combustíveis. Nos últimos anos, a utilização de biocombustíveis visando à substituição parcial ou total de combustíveis fósseis, vem sendo o foco das discussões sobre a utilização de biomassa (DE PAULA, 2009).

A biomassa celulósica tem o potencial de contribuir para atender a demanda por combustível líquido, mas os requisitos de uso de terra e processos ineficientes representam obstáculos para o uso em larga escala de tecnologias de biomassa em biocombustíveis (RUBIN, 2008).

A biomassa vegetal é a mais abundante no mundo o que leva o polissacarídeo celulose a ser, dentre os materiais naturais, o biopolímero com maior potencial biotecnológico (LAUREANO-PEREZ et al., 2005). A abundância da celulose tem estimulado o uso dos processos de fermentações celulolíticas pelo homem (ZHU et al., 2009), inclusive para produção de etanol.

Diferentes tipos de biomassas vegetais são estudadas como potencial fonte de polissacarídeos e seu uso na produção de etanol. As principais fontes e de baixo custo são as biomassas remanescentes da agricultura, como o, sabugo de milho, casca de arroz, bagaço da cana, entre outras, são muitas vezes utilizados com baixo valor agregado.

Contudo, um dos principais problemas com a produção de bioetanol é a disponibilidade de matérias-primas, questão variante segundo a distribuição geográfica e periodização de cultivos. O preço das matérias primas é também altamente volátil o que pode afetar bastante os custos de produção deste biocombustível, uma vez que as matérias primas normalmente representam mais do que um terço dos custos de produção.

Além das biomassas derivadas da agricultura tradicional, são buscadas outras fontes vegetais para a demanda de carboidratos. Vegetais lignocelulósicos produzidos com único fim aos biocombustíveis. Como no caso do uso do sorgo como fonte de celulose e 
hemicelulose para produção de bioetanol (DAMAY et al., 2018), e até mesmo Phalaris aquatica L. uma planta herbácea nativa da região do mediterrâneo (CHRYSIKOU et al., 2018), são estudados como biomassa para produção de etanol.

Um vegetal com potencial para uso como fonte de carboidratos é a Furcraea foetida, possui uma estrutura holocelulósica de aproximadamente 75\% (PIRES, 2009), planta com uso ornamental, produção do sisal, entre outras, ainda não foi estudado visando a obtenção de açúcares fermentescíveis via sacarificação de polissacarídeos.

\section{Furcraea foetida}

A Furcraea foetida, Agave foetida, ou Furcraea gigantea tem sua distribuição original desde o sudeste da América Central até o norte da América do Sul, sendo nativa da região nordeste brasileira (ZAYAS, 1989). Apresenta características como reprodução por brotamento (HUECK, 1953; MOTOOKA et al., 2003), longos períodos de floração e frutificação, pioneirismo, adaptação a áreas degradadas, eficiência no sucesso reprodutivo, além disso, compete com outras plantas por nutrientes e espaço físico (MOTOOKA et al., 2003).

A $F$. foetida apresenta uma conformação estrutural em roseta foliar cujo comprimento pode alcançar de 2,5 a 4,0 m de diâmetro, com folhas pontiagudas, fibrosas, suculentas, dispostas em volta de uma base curta, as folhas podem conter espinhos espaçados em suas margens (MOTOOKA, 2003; PIRANI, CORDEIRO, 2002; YOKOSUKA 2009). Durante o período de reprodução essa planta desenvolve uma inflorescência de 6 a $8 \mathrm{~m}$ de altura no centro da roseta com o formato de uma espiga ramificada (YOKOSUKA 2009). A utilização da espécie $F$. foetida foi comum na região de Praia Mole, Ilha de Santa Catarina, até meados de 1940 e 1950 para a confecção de artefatos do cotidiano da população da época, notando-se que a utilização mais encontrada está relacionada à ornamentação e a construção de cercas vivas (SARMENTO, 2013).

A F. foetida apresenta um potencial ainda desconhecido para a produção de bioetanol, porém como toda biomassa vegetal tem uma estrutura lignocelulósica complexa, necessitando de pré-tratamento para desconstrução dessa estrutura e posterior sacarificação das porções celulósicas e hemicelulósicas.

Esses pré-tratamentos são importantes pois a hidrólise da celulose ou hemicelulose por celulases e hemicelulases resulta na produção final de monossacarídeos. Essas enzimas, porém, por serem proteínas, não conseguem penetrar com facilidade na estrutura lignocelulósica, tendo barreiras como a lignina e até mesmo a estrutura cristalina dos polissacarídeos. 


\section{Pré-tratamentos}

A utilização da biomassa como uma fonte de carboidratos para produtos químicos e combustíveis tem sido severamente dificultada pela baixa eficiência da população microbiana celulolítica. Além disso, a menos que um excesso muito grande de enzimas seja usado, a digestibilidade enzimática da celulose na biomassa nativa é baixa $(<20 \%$ de rendimento), devido à característica estrutural do material lignocelulósico. Em vista disso, biomassas em geral requerem um pré-tratamento para aumentar a digestibilidade e tornar a celulose e até mesmo a hemicelulose mais acessível às enzimas que convertam os carboidratos em açúcares fermentescíveis (FALKOSKI et al., 2013).

Um pré-tratamento eficaz é caracterizado por diversos critérios, tais como evitar a necessidade de reduzir o tamanho das partículas da biomassa e limitar a formação dos produtos da degradação que inibem o crescimento dos microrganismos fermentativos.

A resistência da biomassa lignocelulósica a hidrólise é causada em grande parte pela sua cristalinidade, pela área de superfície acessível, proteção pela lignina, caráter heterogêneo das partículas da biomassa, e o fato da celulose estar revestida pela hemicelulose (VASQUEZ et al., 2007; ARANTES e SADDLER, 2010).

Avaliando-se o potencial de fungos para estes processos, eles são capazes de se desenvolver em meios com altas quantidades de substâncias químicas recalcitrantes, portanto com grande capacidade de degradação da estrutura lignocelulósica, principalmente aos fungos do gênero Trichoderma e Fusarium, que têm apresentado resultados promissores (WANG 2012).

\section{Sacarificação}

O processo de sacarificação consiste no uso de enzimas hidrolíticas que atuam em polissacarídeos (celulose e hemiceluloses) obtendo assim os seus monômeros constituintes na forma de açúcares fermentáveis, passiveis de serem utilizados na produção de biocombustíveis. A conversão da celulose em monômeros de glicose é feita empregando-se enzimas celulolíticas tais como as celobiohidrolases (CBHs), também chamadas de exo-1,4$\beta$-glucanases, as endo-1,4- $\beta$-glucanases (EGs) e as $\beta$-glicosidases (BGs). Estas atuam em diferentes sítios da cadeia celulósica de forma sinérgica: as CBHs atuam clivando ligações glicosídicas nas extremidades da cadeia, obtendo-se como produto as unidades de celobiose; as EGs clivam regiões amorfas internas da cadeia celulósica e as BGs clivam a celobiose (VALADARES 2013). 
As celulases podem ser produzidas por diversos fungos e bactérias. O fungo Trichoderma reesei é o microrganismo mais utilizado industrialmente para a produção de celulases, entretanto, como desvantagem, a sua produção de $\beta$-glicosidase é relativamente pequena. Assim, a aplicação de extrato enzimático proveniente de T. reesei para a degradação da celulose gera altas concentrações de oligômeros. Outro fungo com potencial produção de celulases é o Fusarium, com diversas citações na literatura (MEDVE, 1998; PANAGIOTOU 2004).

\section{Hemiceluloses e Hemicelulases}

As hemiceluloses são polímeros complexos, ramificados, compostos de monossacarídeos e derivados, dentre os quais podemos citar a glicose, xilose, manose, arabinose, ácido 4-O-metilglicurônico e ácido 4-O-metilgalacturônico. Além de seus constituintes, as hemiceluloses diferem da celulose por possuírem um menor grau de polimerização e com presença de ramificações na cadeia principal. Esta cadeia principal é formada por monômeros de pentoses ou hexoses unidos, em geral, por ligações glicosídicas $\beta$-(1-4) com pontos de ramificações unidos à cadeia principal por ligações glicosídicas $\beta$-(12), $\beta(1-3)$ e/ou $\beta$-(1-6) (SHALLOM; SHOHAM, 2003). As hemiceluloses são classificadas de acordo com sua composição, como $\beta$-mananas, galacto-glicomananas, arabinanas, arabinogalactanas.

Dentre as hemiceluloses, as mais abundante são as xilanas. Em comum, as xilanas são compostas por uma cadeia principal de resíduos de xilose unidos por ligações glicosídicas $\beta$ (1-4) nas plantas terrestres, no entanto, cadeias com ligações glicosídicas $\beta$-(1-3) unindo os resíduos de xilose foram caracterizadas em algas, como também foi encontrado cadeias com os dois tipos de ligações em Palmeria palmata (SUBRAMANIYAN; PREMA, 2002).

A degradação da hemicelulose impõe vários desafios aos mais diversos tipos de microrganismos. O polímero é de alto peso molecular, insolúvel ou associado com celulose e lignina. A hemicelulose também é altamente variável na sua estrutura, portanto, diversas enzimas são necessárias para sua completa hidrólise. A degradação da xilana, por exemplo, necessita da ação sinérgica de diversas enzimas. Endo- $\beta$-1,4-xilanase (EC 3.2.1.8), exo$\beta x$ ilosidase (EC 3.2.1.37), $\alpha$-Larabinofuranosidase (EC 3.2.1.55), $\alpha$-glucuronidase (EC 3.2.1), acetil xilano esterase (EC 3.1.1.6), (ácido ferúlico e ácido p-cumárico) esterase (EC 3.2.1). Além desta gama de enzimas envolvidas na degradação da xilana, se olharmos apenas para as endo- $\beta$-1,4-xilanases, por exemplo, veremos como a complexidade das hemiceluloses acarretaram numa gama de endo- $\beta-1,4$-xilanases diferentes (FAIK, 2010) 


\section{Enzimas fúngicas}

Em geral, os fungos que decompõem substâncias celulósicas são encontrados no solo, colonizando vegetais, suas raízes e resíduos, com importante função de reciclagem de nutrientes. A atividade fúngica depende do conteúdo de matéria orgânica no solo, a qual determina sobremaneira a ocorrência e a distribuição desses organismos (RUEGGER, TAUKTORNISIELO, 2004).

Os fungos, em função de suas características de reprodução e crescimento, adaptamse a diversos substratos, entre os quais efluentes de indústrias processadoras de alimentos, resíduos agrícolas e agroindustriais (TAVARES et al., 1998). Assim, são capazes de degradar a celulose e hemicelulose e utilizá-las como fonte de carbono e energia; inclusive os fungos filamentosos, considerados uma classe de microrganismos de grande significado comercial e amplamente distribuídos na natureza, encontrados em solos, em vegetais e animais, podendo ter hábitos saprófitos ou parasitas (GRIMM et al., 2005).

As enzimas celulolíticas fúngicas têm sido estudadas devido ao seu potencial biotecnológico (NG, 2004). Entre os produtores de celulases e hemicelulases estão os gêneros: Aspergillus, Penicillium e Trichoderma (LYND et al., 2002). Os fungos do gênero Trichoderma são considerados grandes secretores de celulases e hemicelulases, sendo geneticamente os mais estudados. Os fungos produzem um grupo complexo de celulases capazes de clivar as ligações $\beta$ - $(1 \rightarrow 4)$-glicosídicas presentes na celulose e derivados de celulose (ORTEGA et al., 2001).

O Gênero Fusarium grupo é um grande táxon polifilético de fungos do Filo Ascomycota, encontrado no solo e capaz de crescer em uma ampla gama de substratos, em associação, muitas vezes patogênicas, com plantas. São isolados em diversas condições climáticas, sendo predominantes em ambientes temperados e tropicais (TEETOR-BARSCH; ROBERTS, 1983; COLEMAN et al., 2011; SUMMERELL e LESLIE, 2011).

Esse gênero tem em seu histórico ataques a diversas culturas de grande relevância econômica, como tomate, banana, pimenta, berinjela, feijão, girassol, trigo, milho. Muitas cepas do gênero Fusarium vem sido referenciadas como grandes produtoras enzimáticas de celulases e hemicelulases, sendo capaz de se desenvolver em ambientes com alta presença de substancias recalcitrantes (PERALDI et al., 2011, FORTUNATO et al., 2012).

Estudos têm mostrado que, além das celulases, a presença de enzimas acessórias é muito importante para a formulação de um bom coquetel enzimático. Associações de celulases e hemicelulases contribuem para uma hidrólise mais eficiente da biomassa, e uma maior produção de monossacarídeos. O uso de xilanases em sinergismo com celulases, tem 
apresentado bons resultados, reduzindo a adição de celulases e levando à liberação quase total da glicose da biomassa (HU et al. 2011).

A eficiência da sacarificação enzimática também pode ser influenciada pela inibição das endoglicanases e exoglicanases pelos produtos finais de hidrólise, a celobiose e glicose (DUFF; MURRAY, 1996). Este fato, entretanto, pode ser amenizado pela suplementação de Bglicosidase ao coquetel enzimático ou então promovendo as etapas de sacarificação e fermentação simultaneamente (OLOFSSON et al., 2008).

Desta forma, a busca por diferentes tipos de biomassas com potencial biotecnológico na produção de combustíveis, além de estudar formas de pré-tratamentos eficientes e ambientalmente seguras e a produção de enzimas capazes de hidrolisar os carboidratos da biomassa na sacarificação, são pontos chaves na produção do etanol celulósico de forma viável economicamente.

\section{Material e Métodos}

\section{Pré-tratamento biológico com fungos}

As folhas usadas da Furcraea foetida foram picadas e secas em estufa de circulação forçada a $50^{\circ} \mathrm{C}$. As amostras foram então trituradas em moinho de pás adquirindo uma composição fina ideal para o cultivo. As biomassas foram então pré-tratadas com fungos da podridão branca Pleurotus ostreatus e Ganoderma lucidum, isoladamente. O cultivo utilizando o Fusarium lateritium var. majus foi utilizado como forma de pré-tratamento e aproveitar o seu potencial como produtor de enzimas para uso na sacarificação. Os fungos $P$. ostreatus e G. lucidum foram inoculados para fermentação em estado sólido a partir de discos miceliais com $10 \mathrm{~mm}$ de diâmetro, com $10 \%$ do peso nas diferentes fibras. As cepas de $F$. Lateritium foram inoculadas a partir de suspensões de esporos $10^{6}$. As amostras foram mantidas estáticas, no escuro a $37^{\circ} \mathrm{C}$, em frascos erlenmeyer de $0,125 \mathrm{~L}$ com $10 \mathrm{~g}$ de fibra, suplementado com meio de Vogel (VOGEL, 1956), glicose 0,5\% e extrato de levedura 0,2\%, com umidade final variando de 65 a 82\%, sendo extraídas após o pré-tratamento após adição de 0,025 L de água destilada. Filtrou-se os materiais insolúveis de cada um dos frascos sendo a biomassa restante seca à $50^{\circ} \mathrm{C}$ em estufa de circulação forçada até peso constante. Os materiais solúveis foram utilizados para outras análises. Em relação aos tempos de cultivo, foram realizados testes com diferentes dias de pré-tratamento, variando de 15 e 45 dias, observando o crescimento do fungo sobre a fibra e a degradação da lignina, além do rendimento de açúcares redutores. 


\section{Determinação das atividades enzimáticas}

Os materiais solúveis foram utilizados para determinação das atividades das principais enzimas ligninolíticas e celulolíticas.

\section{Lacase}

A atividade da lacase foi determinada para os cultivos de Pleurotus ostreatus e Ganoderma lucidum, sendo realizada à $40^{\circ} \mathrm{C}$ usando ABTS como substrato. A mistura de reação foi preparada com $200 \mu \mathrm{l}$ de ABTS (10mM), $100 \mu 1$ do filtrado em 1,7 ml de tampão acetato de sódio 50mM (pH 4,0). O aumento da absorbância foi monitorado a $420 \mathrm{~nm}$ (SHIN; LEE, 2000).

\section{Manganês peroxidase}

As atividades de Manganês Peroxidase foram determinadas para as cepas de Pleurotus ostreatus e Ganoderma lucidum. A mistura de reação continha $0,2 \mathrm{~mL}$ de $\mathrm{MnSO}_{4} 10 \mathrm{mM}, 0,2$ $\mathrm{mL}$ de $\mathrm{H}_{2} \mathrm{O}_{2}$ 0,5 mM e 0,2 mL do extrato enzimático em tampão malonato 50mM, pH 4,5. Os íons mangânicos gerados pela ação da enzima formam um complexo com o malonato que absorve em $270 \mathrm{~nm}$ (WARIISHI et al., 1992)

\section{Beta-glicosidase}

A atividade de $\beta$-gicosidases foram determinadas para os cultivos de Pleurotus ostreatus e Ganoderma lucidum utilizando-se os substratos sintéticos o-nitrofenil-betaglicopiranosídeo, incubando-se este substrato em tampão citrato $50 \mathrm{mM}, \mathrm{pH} 5,4$ com o filtrado a $50^{\circ} \mathrm{C}$ durante 10 min. A reação foi parada com adição de tetraborato de sódio, em seguida medido espectrofotometricamente a $410 \mathrm{~nm}$ (LENARTOVICZ et al., 2003).

\section{Amilase, xilanase e celulase}

A Atividade dessas enzimas foram determinadas para todos os cultivos fúngicos, utilizando-se os substratos amido, xilano e carboximetilcelulose, respectivamente pelo surgimento de açúcares redutores utilizando o método do ácido 3,5 dinitrosalicílico (DNS) (MILLER, 1959).

\section{Determinações de fenólicos}

Os fenólicos totais presentes nos materiais foram avaliados pelo método de Singleton et al. (1999) para todos os cultivos, utilizando vanilina como padrão. As fibras pré-tratadas com os fungos, e os resíduos lignocelulósicos controles sem pré-tratamento, foram submetidas a sacarificação. A sacarificação foi realizada utilizando dois pools enzimáticos comerciais contendo enzimas celulolíticas (Cellic-CTec2) e hemicelulolíticas (Cellic-HTec2), fornecidos pela empresa Novozymes. Além disso, foi utilizado o pool enzimático produzido a partir do 
crescimento do $F$. Lateritium sobre as fibras de $F$. Foetida, na forma de extrato bruto com alta presença de xilanases.

\section{Sacarificação}

As sacarificações foram realizadas com $0,5 \mathrm{~g}$ de $F$. foetida pré-tratadas e sem prétratamentos, em tampão citrato de sódio $50 \mathrm{mM}\left(\mathrm{pH} \mathrm{5,0),} \mathrm{a} 37^{\circ} \mathrm{C}\right.$, com volume final de 10 $\mathrm{mL}$, agitação de $150 \mathrm{rpm}$ por 72 horas, utilizou-se de $1 \mathrm{~mL}$ do pool enzimático comercial e 9 $\mathrm{mL}$ do pool enzimático do $F$. Lateritium. O processo de sacarificação utilizando o pool HTec2 e o pool FLM foi realizado em fibras de Furcraea foetida pré-tratadas ou não pelo cultivo de Fusarium lateritium var. Majus. A sacarificação com o pool CTec2 foi realizado nas fibras de F. foetida não tratadas e pré-tratadas com a cepa de Pleurotus ostreatus. Após 72 horas de sacarificação foram realizadas as análises de açúcares redutores presentes, para avaliar o rendimento dos cultivos. Os açúcares redutores liberados na sacarificação foram quantificados pelo método do DNS (MILLER, 1959).

\section{Análise estatística dos dados experimentais}

Os experimentos foram realizados pelo menos em triplicata. Os resultados serão expressos como a média, \pm erro padrão da média. A análise da significância da diferença entre duas médias será feita através do teste $t$ de Student.

\section{Resultados e Discussão}

\section{Crescimento dos microrganismos e dosagens enzimáticas}

A biomassa de F. Foetida tem sua utilização pautada principalmente na ornamentação, cercas vivas e até para produção de fibras de Sisal, porém a utilizada da holocelulose como potencial para produção de combustíveis ainda não foi explorada. Como toda fibra lignocelulósica há a necessidade de um pré-tratamento que facilite o acesso para as enzimas celulolíticas e hemicelulolíticas à fibra, assim foi realizado pré-tratamentos biológicos utilizando fungos, além disso avaliou-se a produção de enzimas como potencial para sacarificação enzimática da fibra pré-tratada.

Os fungos basidiomicetos Ganoderma lucidum e Pleurotus ostreatus, além do ascomiceto Fusarium Lateritium var. majus foram cultivados sobre as folhas de Furcraea Foetida. Após o período de cultivo de 45 dias para os basidiomicetos e 15 dias para o ascomiceto, foram interrompidos para análises enzimáticas e uso da biomassa para sacarificação. 
Os tempos de 15 dias para o $F$. Lateritium foram suficientes para o crescimento completo na fibra, porém para os basidiomicetos P. ostreatus e G. lucidum, o crescimento foi mais lento, necessitando de um período de pré-tratamento maior (45 dias).

Figura 1. Atividade das enzimas Xilanase e Celulase nos cultivos do G. Lucidum, P. Ostreatus e Fusarium Lateritium var. Majus extraídos dos respectivos cultivos sobre a Furcraea foetida. Cultivos realizados pelo menos em triplicata. Letras iguais indicam resultados estatisticamente iguais para cada pool enzimático utilizado, segundo teste ANOVA $(\mathrm{P}<0.05)$.
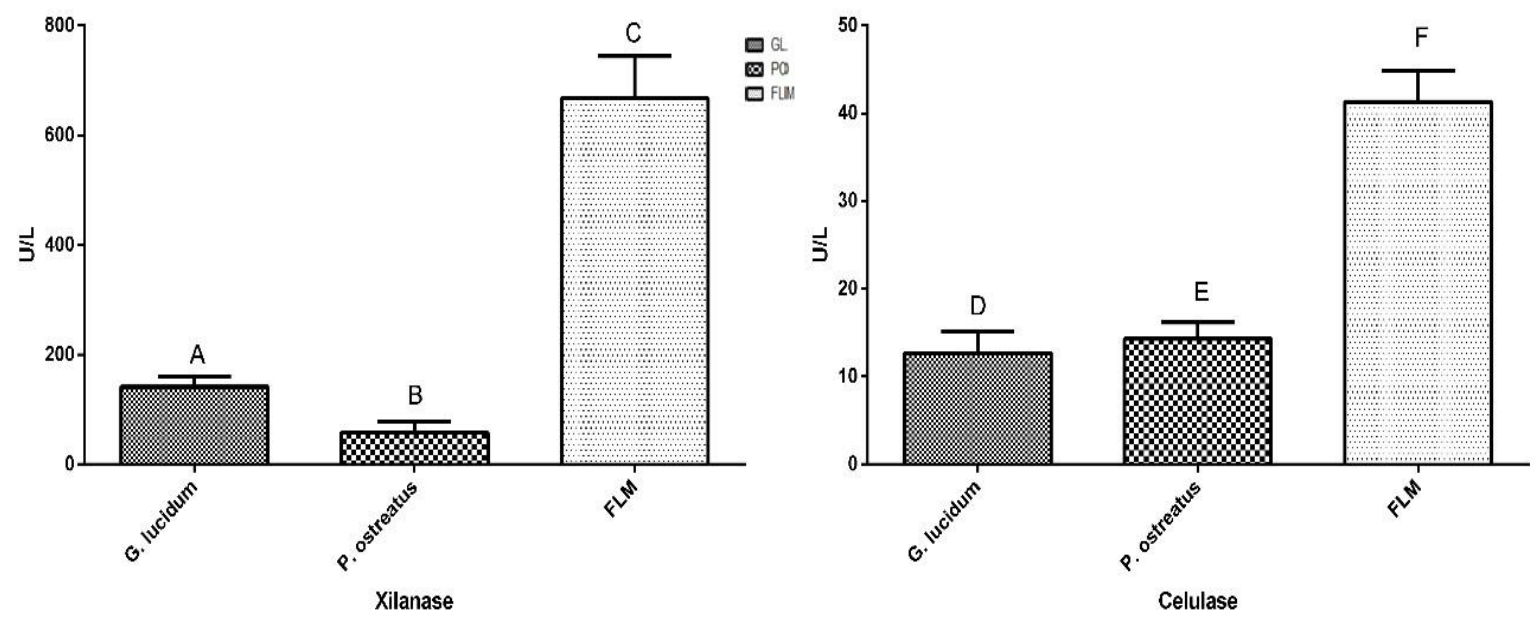

Fonte: Autor (2020)

Ao analisar a produção de xilanase e celulase nos três tipos de cultivo, observou-se uma maior produção dessas enzimas pelo $F$. Lateritium (Figura 1). Uma maior produção de enzimas celulolíticas e hemicelulolíticas nos ascomicetos é esperado em comparação com os basidiomicetos. A produção dessas enzimas está relacionada a grande proporção de celulose e hemicelulose presente na F. Foetida. A Furcraea Foetida apresenta proporções de aproximadamente $75 \%$ de holocelulose, com $22 \%$ de hemicelulose e $52 \%$ de celulose, e ainda $8 \%$ de lignina (PIRES, 2009).

Os fungos do gênero ascomiceto como o F. Lateritium e microbiotas parecidas como o Trichoderma reesei são organismos conhecidos por melhor atuarem em sistemas celulósicos e hemicelulósicos, pela sua produção razoável de celulases e hemicelulases (ELISASHVILI, 1993). A produção destas enzimas pelos ascomicetos já foi contrastada frente a fungos da ordem dos basidiomicetos, onde o padrão de produção dessas enzimas em cultivos feitos na cana de açúcar, em períodos de tempo semelhantes, se mostrou superior (MAMEDE, et al., 2008).

A produção aumentada de xilanase e celulase pelo $F$. Lateritium na biomassa de $F$. Foetida após 15 dias de cultivo, mostra que o pool enzimático produzido tem potencial para uso na sacarificação, discutido posteriormente no tópico 5.3. Sacarificação enzimática. 
GAETA, G. T. et al.

Tabela 1. Atividade das enzimas $\beta$-Xilosidase, $\beta$-Glicosidase, Manganês Peroxidase e Lacase nos cultivos de G. Lucidum e P. Ostreatus extraídos dos respectivos cultivos sobre a Furcraea foetida. Cultivos ao menos em triplicata. Letras iguais indicam resultados estatisticamente iguais para cada pool enzimático utilizado, segundo teste $\mathrm{t}$.

\begin{tabular}{|l|l|l|}
\hline Enzimas (U/L) & Ganoderma lucidum & Pleurotus ostreatus \\
\hline $\boldsymbol{\beta}$-xilosidase & $119,15 \pm 9,67^{\mathrm{a}}$ & $129,25 \pm 24,59^{\mathrm{a}}$ \\
\hline $\boldsymbol{\beta}$-glicosidase & $135,18 \pm 11.57^{\mathrm{b}}$ & $114.84 \pm 9.60^{\mathrm{c}}$ \\
\hline Manganês Peroxidase & $180,61 \pm 25,86^{\mathrm{d}}$ & $174,55 \pm 13,13^{\mathrm{d}}$ \\
\hline Lacase & $159,94 \pm 16,54^{\mathrm{e}}$ & $366,77 \pm 30,15^{\mathrm{f}}$ \\
\hline
\end{tabular}

Fonte: Autor (2020)

Análises das enzimas $\beta$-xilosidase, $\beta$-glicosidase, Mn Peroxidase e Lacase foram realizadas para os cultivos do P. ostreatus e G. lucidum na F. Foetida após 45 dias (Tabela 1). As enzimas $\beta$-xilosidase, $\beta$-glicosidase e Mn Peroxidase apresentaram suas produções constantes comparando G. lucidum com P. ostreatus. Enzimas peroxidases parecem apresentar uma expressão menor nestes tipos de cultivos (MAMEDE, et al., 2008).

Uma diferença encontrada foi em relação a $\beta$-glicosidase, com maior produção pelo fungo G. lucidum, com um aumento de cerca de $20 \%$. Os valores de enzimas encontrados são considerados baixos, mostrando que esses fungos não são grandes produtores dessas enzimas.

Por outro lado, dosagens enzimáticas da enzima Lacase apresentaram diferenças entre os cultivos de $P$. ostreatus e G. lucidum, sendo a atividade apresentado pelo extrato enzimático resultante do tratamento com $P$. ostreatus cerca de 2,29 vezes maior que o tratamento com $G$. lucidum. (Tabela 1).

Os mecanismos para a degradação de lignina são variados entre os fungos, gerando diversos possíveis mecanismos para a degradação desses compostos (HATAKKA, 1994). O fungo $P$. ostreatus é conhecido por degradar lignina, sendo elevada a atividade de Lacases expressas por tais fungos em longos períodos de crescimento em meios de cultivo sólidos, é uma espécie que apresenta um mecanismo adaptativo para a degradação da lignina em diferentes condições.

\section{Expressão de fenólicos totais nas biomassas pré-tratadas}

A dosagem de fenólicos totais revelou uma queda considerável com relação a biomassa íntegra da Furcraea Foetida utilizada no cultivo, sendo a cepa de $P$. ostreatus a mais eficiente nesse quesito, apresentando uma redução de 93,51\% dos compostos fenólicos presentes no meio, seguida pelo G. lucidum com uma redução de 88,46\%, e pelo F . Lateritium de 80,19\% (Figura 2). Estes resultados mostram a eficiência do pré-tratamento na redução e possível degradação de tais compostos fenólicos como relatado por Rouches et al. (2015). 
Figura 2. Comparação da concentração de compostos fenólicos totais solúveis, extraídos dos extratos de Furcraea foetida íntegra e pré-tratada com os diferentes fungos. Letras iguais indicam resultados estatisticamente iguais para cada pool enzimático utilizado, segundo teste ANOVA $(\mathrm{P}<0.05)$.

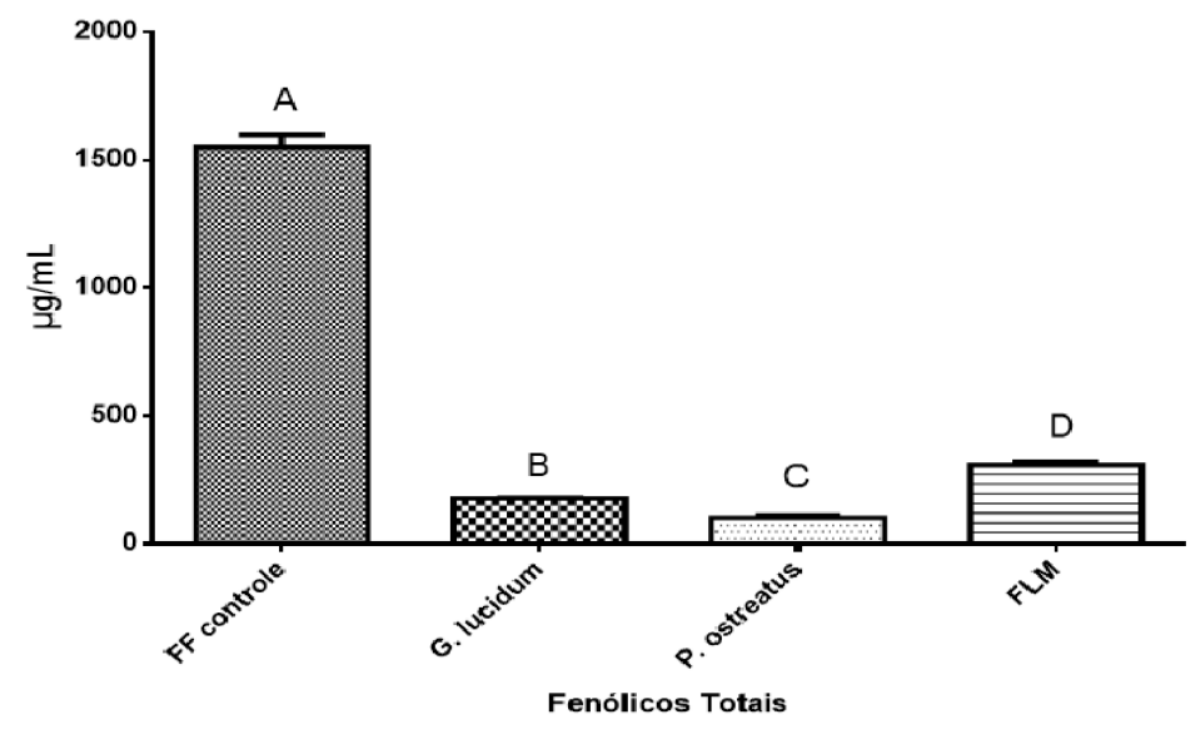

Fonte: Autor (2020)

As folhas de F. Foetida possuem alta expressão de fenólicos totais solúveis (MATHEW, ARORA, 2012). E esta alta quantidade de fenólicos encontradas na Furcraea foetida está relacionado ao seu sistema de defesa, bem conhecido por essas espécies de plantas, no qual é confirmado pela dificuldade de qualquer crescimento fúngico sobre as mesmas em ambiente natural (MATHEW, ARORA, 2012). Em nossos cultivos as reduções foram consideráveis, demonstrando que os fungos estudados foram capazes de se adaptar e crescer em um meio rico em fenólicos.

A maior degradação de fenólicos ocorreu no cultivo do Pleurotus ostreatus, o mesmo cultivo no qual apresentou a maior produção de Lacase, podendo está enzima estar relacionada a forte diminuição dos compostos fenólicos, utilizado como um recurso adaptativo para permitir o crescimento do fungo, pois a enzima Lacase é uma polifenol oxidase, pertencente à classe de enzimas oxidorredutase (MAYER, STAPLES, 2002).

\section{Sacarificação enzimática}

A sacarificação enzimática é parte importante para a produção de açúcares, pois a celulose e a hemicelulose precisam ser degradas em açúcares fermentáveis. Na sacarificação utilizam-se principalmente de celulases, $\beta$-glicosidases, xilanases, $\beta$-xilosidases entre outras.

Para avaliar o pré-tratamento biológico com uso de fungos foi realizada a sacarificação utilizando o pool enzimático da Cellic-CTec2 e Cellic-HTec2, com presenças predominantes de enzimas celulolíticas e hemicelulolíticas, respectivamente. Além disso, foi utilizado o pool 
enzimático produzido pelo fungo F. lateritium var. majus sobre as folhas da Furcraea foetida, esse pool enzimático foi utilizado em extrato bruto com predominância de xilanase.

Figura 3. Açúcares redutores liberados após 72 horas de sacarificação com o pool enzimático CTec2. Biomassa de Furcraea foetida controle sem pré-tratamento (FF controle CTec2) e a Furcraea foetida pré-tratada com Pleurotus ostreatus durante 45 dias (FF pré-tratada PO CTec2). Letras iguais indicam resultados estatisticamente iguais para cada pool enzimático utilizado, segundo teste $\mathrm{t}(\mathrm{P}<0.05)$.

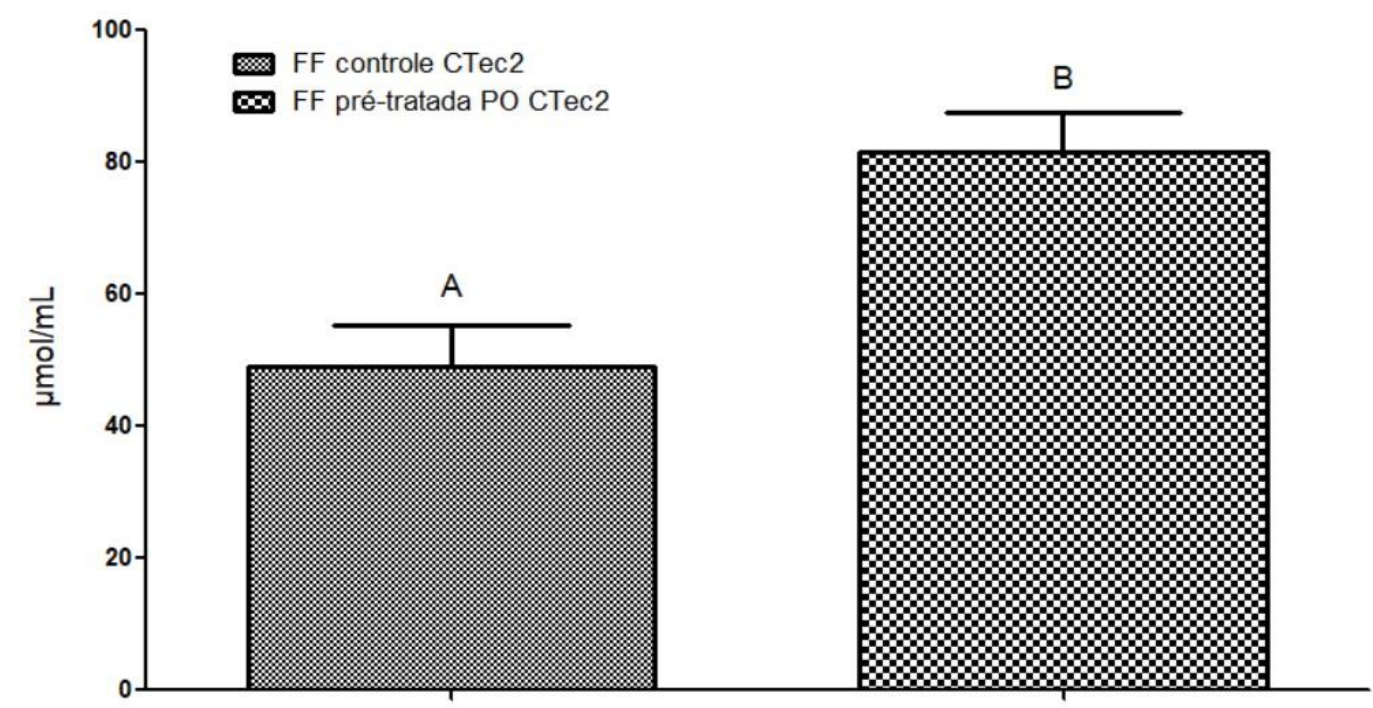

Fonte: Autor (2020)

A avaliação do pré-tratamento utilizando o Pleurotus ostreatus por 45 dias sobre a $F$. Foetida foi utilizado o pool enzimático da CTec2 (Figura 3). A sacarificação com a F. Foetida controle apresentou 49,08 $\pm 8,62 \mu \mathrm{mol} / \mathrm{mL}$ de açúcares redutores, em contraste a $F$. Foetida pré-tratada que apresentou liberação de $81,61 \pm 8,43 \mu \mathrm{mol} / \mathrm{mL}$. Portanto, o pré-tratamento biológico com $P$. ostreatus proporcionou uma melhora de $66,3 \%$ em relação ao controle, demonstrando ser uma forma de pré-tratamento eficiente.

Ao compararmos com sacarificações feitas em Lantana Camara, uma espécie invasora da região dos trópicos americanos da família das verbenáceas, a mesma foi submetida a um prétratamento ácido para deslignificação e posterior sacarificação enzimática, e se obteve um aumento no rendimento da sacarificação de aproximadamente 77,7\% (RAMESH et al 2010). Outros processos apresentaram melhoras de 67,6\%,80,0\% e 70,0\% para pré-tratamentos com clorito no bagaço de cana (ADSUL et al., 2005), P. Juliflora (JEYA et al., 2009), e tratamento alcalino para palha de arroz (GUPTA et al., 2009), respectivamente. Isso demonstra que um pré-tratamento biológico de longo prazo, possibilitando a degradação de diversos componentes da parede celular da planta, apresenta uma melhora no processo de sacarificação comparável a métodos ácidos ou alcalinos de pré-tratamento. O tempo de cultivo estendido, 
pode consistir de uma boa estratégia para a degradação desses compostos frente a tratamentos químicos gerais, gerando biomassas mais propicias para o posterior tratamento enzimático.

Além da utilização da porção celulósica das biomassas para produção de combustíveis, como o etanol de segunda geração, a porção hemicelulósica também pode ser explorada, principalmente na utilização das pentoses. Atualmente, se trata de um grande desafio o uso da hemicelulose para o processo fermentativo, devido a boa parte dos pré-tratamentos existentes constituírem de sua remoção, porém o uso de microrganismos produtores de tais enzimas capazes de hidrolisar as variadas estruturas que a hemicelulose pode assumir, demonstra uma alternativa sustentável para o mesmo (GÍRIO et al. 2010). O uso desse tipo de pré-tratamento ainda abre a opção da engenharia genética, para a produção e expressão de enzimas responsáveis pela lise destas estruturas e pelas vias de fermentação dos açúcares gerados, em especial as pentoses como a xilose (VLEET et al 2009)

$\mathrm{Na}$ análise do pré-tratamento realizado pelo fungo $F$. lateritium, com um cultivo de apenas 15 dias, não observou-se melhora estatística na liberação de açúcares em relação ao controle sem pré-tratamento, tanto nas análises do pool enzimático HTec2 quanto do pool FLM.

Figura 4. Açúcares redutores liberados após 72 horas de sacarificação utilizando os pools enzimáticos HTec2 e Pool FLM. Biomassa de Furcraea foetida controle sem pré-tratamento com o pool HTec2 (FF controle HTec2); biomassa de Furcraea foetida pré-tratada com Fusarium lateritium var. majus durante 15 dias com o pool HTec2 (FF pré-tratada FLM HTec2); biomassa de Furcraea foetida controle sem pré-tratamento com o pool FLM (FF controle Pool FLM); e biomassa de Furcraea foetida pré-tratada com Fusarium lateritium var. majus durante 15 dias com o pool FLM (FF pré-tratada FLM Pool FLM).

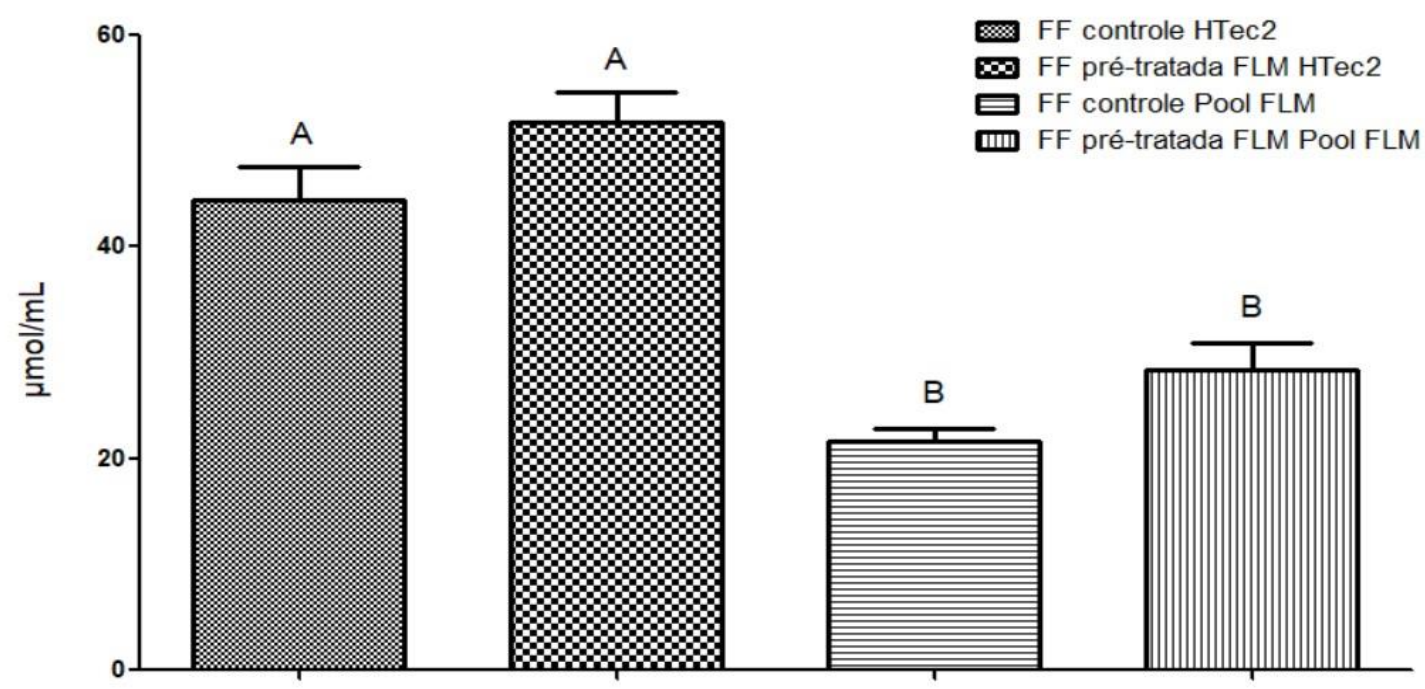

Letras iguais indicam resultados estatisticamente iguais para cada pool enzimático utilizado, segundo teste $\mathrm{t}(\mathrm{P}<0.05)$.

O pool enzimático HTec2 apresenta uma quantidade considerável de hemicelulases, assim observa-se que a liberação de 44,49 $\pm 4,26 \mu \mathrm{mol} / \mathrm{mL}$ e $51,84 \pm 3,92 \mu \mathrm{mol} / \mathrm{mL}$ no 
controle sem pré-tratamento da $F$. foetida e no pré-tratado pelo $F$. lateritium, respectivamente, refere-se basicamente a açúcares da porção da hemicelulose da F. Foetida.

Ao testar o pool enzimático, retirado do extrato bruto do pré-tratamento de $F$. lateritium na F. Foetida observou-se uma menor eficiência do que o pool enzimático da HTec2, resultado este explicado pois o pool enzimático da Novozymes apresenta um concentrado de altas taxas de hemicelulases e em proporções maiores do que os utilizados no pool enzimático do F. lateritium.

A liberação de açúcares apresentou valores de 28,27 $\pm 3,61 \mu \mathrm{mol} / \mathrm{mL}$ e 21,61 \pm 1,81 $\mu \mathrm{mol} / \mathrm{mL}$, na $F$. Foetida pré-tratada com $F$. lateritium e na $F$. Foetida controle, respectivamente. Apesar de não haver mudança estatística entre os valores, é uma forma de tratamento no qual aproveitou-se o mesmo extrato bruto do pré-tratamento biológico para uso na sacarificação, caminho promissor quando se espera maior eficiência dos processos industriais.

A baixa liberação de açúcares redutores pela $F$. Foetida mesmo com baixa presença de lignina, leva a possibilidade que o maior entrave na utilização da $F$. Foetida como potencial para produção de etanol celulósico é a complexidade da estrutura da holocelulose, e nossa forma de pré-tratamento biológico mostrou-se parcialmente satisfatório. A celulose, principalmente, é uma estrutura de difícil degradação pois possui uma complexidade estrutural, além das cristalizações que os polímeros que compõem a mesma podem apresentar. Outro ponto é a grande variação em termos de composição, requerendo o uso de uma diversidade de enzimas endo e exoglucanases da quais os microrganismos utilizados nesses tipos de cultivos podem ser deficitários ou terem baixa expressão (SANTOS et al, 2012).

\section{Conclusões}

A Furcraea foetida tem potencial para produção de etanol, por ser uma biomassa com alta proporção de polissacarídeos. O pré-tratamento biológico da biomassa lignocelulósica utilizando-se de fungos mostrou-se competitivo frente a outros métodos de deslignificação, mesmo com a alta presença de fenólicos. Os rendimentos com a sacarificação enzimática foram superiores comparando as biomassas pré-tratadas e controles sem pré-tratamento com uso do pool enzimático da CTec2. No entanto ao utilizar o pool enzimático da HTec2 e do extrato bruto do F. lateritium var. majus não houve diferença na liberação de açúcares antes e após os pré-tratamentos. Porém, o pool enzimático do pré-tratamento da F. Foetida com $F$. lateritium var. majus chegou a valores de quase $50 \%$ da liberação de açúcares redutores do pool enzimático comercial da HTec2. Além disso, o fungo Fusarium lateritium var. majus 
mostrou ser um bom produtor de xilanases, com possibilidade do uso das mesmas para sacarificação da porção hemicelulósica da biomassa da $F$. foetida.

\section{Referências}

ADSUL M. G.; GHULE J. E.; SHAIKH H. Enzymatic hydrolysis of delignified bagasse polysaccharides. Carbohydr. Polym. 62, 6-10. 2005.

ARANTES, V.; SADDLER, J. N. Access to cellulose limits the efficiency of enzymatic hydrolysis: the role of amorphogenesis. Biotechnology for biofuels, v. 3, p. 4, 2010.

CHRYSIKOU L. P.; BEZERGIANNI S.; KIPARISSIDES C. Environmental analysis of a lignocellulosic-based biorefinery producing bioethanol and high-added value chemicals. Centre for Research \& Technology Hellas, Greece 2018.

COLEMAN J. J.; MUHAMMED M. Fusarium pathogenesis investigated using Galleria mellonella as a heterologous host. Harvard Medical School, Massachusetts General Hospital, Division of Infectious Diseases, USA. 2011.

DAMAY J.; BOBOESCU I. J.; DURET X. A novel hybrid first and second generation hemicellulosic bioethanol production process through steam treatment of dried sorghum biomass. Bioresourse Technology. V. 263, p. 103-111. 2018.

DE PAULA, M. P. Hidrólise ácida de polpa de sisal: características do processo heterogêneo e estudo das reações correlatas. Dissertação (Mestrado em Ciências FísicoQuímica) - Instituto de Química de São Carlos, Universidade de São Paulo, São Carlos. 2009.

ELISASHVILI, V.L.; Biosynthesis and properties of celulases and xylanases of higher Basidiomycetes. Applied Biochemistry and Microbiology, New York, v. 29, p. 257-266, 1993.

FAIK, A. Xylan biosynthesis: news from the grass. Plant physiology, v. 153, n. 2, p. 396402, 2010.

FALKOSKI, D. L. et al. Chrysoporthe cubensis: A new source of cellulases and hemicellulases to application in biomass saccharification processes. Bioresource Technology, v. 130, p. 296- 305, 2013.

FORTUNATO A. A.; RODRIGUES F. A. Physiological and biochemical aspects of the resistance of banana plants to Fusarium wilt potentiated by silicon. Phytopathology 102:957-966. 2012.

GÍRIO F.M. ; FONSECA C.; DUARTE L.C.; Hemicelluloses for fuel ethanol: A review. Laboratório Nacional de Energia e Geologia, Lisboa, Portugal 2010.

GRIMM. L, H, KELLY, S., KRULL, R, HEMPEL, D. C. Morphology and production of filamentous fungi. Applied Microbiology Biotechonology, v. 69, p. 375-384, 2005. 
GUPTA R.; SHARMA K. K.; KUHAD R. C. Separate hydrolysis and fermentation (SHF) of Prosopis juliflora, woody substrate for the production of cellulosic ethanol by Saccharomyces cerevisiae and Pichia stipitis NCIM 3498. Bioresour. Technol. 100, 1214-1220. 2009.

HATAKKA, A. Lignin-modifying enzymes from selected white-rot fungi: production and role in lignin degradation. FEMS Microbiology Reviews 13:125-135 (1994).

HU, J.; ARANTES, V.; SADDLER, J. N. The enhancement of enzymatic hydrolysis of lignocellulosic substrates by the addition of accessory enzymes such as xylanase: is it an additive or synergistic effect? Biotechnology for Biofuels, v. 4, n. 1, p. 36, 2011.

HUECK, K. Problemas e importância prática da fitossociologia no Estado de São Paulo. Secretaria da Agricultura do Estado de São Paulo: Instituto de Botânica. Série Contribuições para a pesquisa fitossociológica paulista, São Paulo, V.1, 1953.

JEYA M.; ZHANG Y.-W.; KIM I.-W. Enhanced saccharification of alkali-treated rice straw by cellulase from Trametes hirsuta and statistical optimization of hydrolysis conditions by RSM. Bioresour. Technol. 100, 5155- 5161. 2009.

LAUREANO-PEREZ, L. et al. Understanding factors that limit enzymatic hydrolysis of biomass. Applied Biochemistry and ..., v. 124, n. 1-3, p. 1081-1099, 2005.

LENARTOVICZ, V., SOUZA, C.G.M., MOREIRA, F.G., PERALTA, R.M. Temperature and carbon source affect the production and secretion of a thermostable $\beta$-xylosidase by Aspergillus fumigatus. Process Biochemistry, 38, 1775-1780, 2003.

LYND L.R.; WEIMER P.J.; VAN W.H. Microbial cellulose utilization: Fundamentals and biotechnology. Micro. \& Mol.Bio.Rev., 66: 506-577. 2002.

MAMEDE J. M., et al., Análise enzimática de fungos lignocelulolíticos cultivados em vinhaça e bagaço de cana de açucar. Dissertação (Dissertação em Agronomia) Universidade de São Paulo, Piracicaba. p. 56-60. 2008.

MATHEW J., ARORA K. M., MAZUMDAR A. Evaluation of phytochemical composition and antioxidant activity of aqueous extract of Barleria mysorensis and Furcraea foetida leaves. Molecular and Microbiology Research Laboratory, Environmental Biotechnology Division, School of Bio Sciences and Technology, VIT University, Vellore, Tamil Nadu - 632 014, India 2012.

MAYER, A.M., STAPLES, R.C. Laccase: new functions for an old enzyme. Phytochemistry 60:551-565 (2002).

MEDVE, J., KARLSSON, J., LEE, D., TJERNELD, F., Hydrolysis of Microcrystalline Cellulose by Cellobiohydrolase I and Endoglucanase II from Trichoderma reesei:

Adsorption, Sugar Production Pattern, and Synergism of the Enzymes. Forest Products Biotechnology, Faculty of Forestry, University of British Columbia, Vancouver, Canada, 1998.

MOTOOKA, P. et al. Weeds of Hawai'i's Pastures and Natural Areas: An Identification and Management Guide. College of Tropical Agriculture and Human Resources, University of Hawai'I, Mänoa, 2003. 
OLOFSSON, K.; BERTILSSON, M.; LIDÉN, G. A short review on SSF - an interesting process option for ethanol production from lignocellulosic feedstocks. Biotechnology for biofuels, v. 1, n. 1, p. 7, 2008.

ORTEGA, N., BUSTO, M.D., PEREZ-MATEOS. Kinetics of celulose saccharification by Trichoderma reesei cellulases. International Biodeterioration \& Biodegaradation, v. 47, p. 714, 2001.

PANAGIOTOU, G., CHRISTAKOPOUlOSB, P., OLSSON, L. Simultaneous saccharification and fermentation of cellulose by Fusarium oxysporum F3 - growth characteristics and metabolite. Center for Microbial Biotechnology, Biocentrum-DTU, Building 223, Technical University of Denmark, DK-2800 Kgs. Lyngby, Denmark, 2004.

PERALDI, A., BECCARI, G., STEED, A., NICHOLSON, P. Brachypodium distachyon: a new pathosystem to study Fusarium head blight and other Fusarium diseases of wheat. BMC Plant Biology. v.11. p.100. 2011.

PIRANI, J.R.; CORDEIRO, I. Agavaceae, p.7-8. In: Wanderley M.G.L.; Shepherd, G.J. \& Giulietti, A.M.(Coord.). Flora Fanerogâmica do Estado de São Paulo. FAPESP: HUCITEC, São Paulo. V.2, 2002.

PIRES, J.S.C.; Fibras naturais: Características químicas e potenciais aplicações. Universidade Estadual Paulista "Julio de Mesquita Filho", Instituto de Biociências, Botucatu, São Paulo. P. 39-46, 2009.

RAMESH C. K.; GUPTA R.; KHASA Y. P. Bioethanol production from Lantana camara (red sage): Pretreatment, saccharification and fermentation. Bioresource Technology $101 \mathrm{p}$. 8348-8354 2010.

ROUCHES E.; HERPOEL-GIMBERT I.; STEYER J.P. Improvement of anaerobic degradation by white-rot fungi pretreatment of lignocellulosic biomass: A review. Renewable and Sustainable Energy Reviews 59 179-198, 2016.

RUBIN, E. M. Genomics of cellulosic biofuels. Nature, vol. 454, no. 7206, pp. 841-845, 2008.

RUEGGER, M. J. S. e TAUK-TORNISIELO, S. M. Atividade da celulase de fungos isolados do solo da Estação Ecológica de Juréia-Itatins, São Paulo, Brasil. Revista Brasileira Botânica, v.27, p. 205-211, 2004.

SANTO F. A.; COLODETTE J. L.; FERNANDES S. A. Potential of Sugarcane Straw for Ethanol Production. Quimíca Nova, Universidade Federal de Viçosa, Minas Gerais, Brasil. Vol. 35, No. 5, p. 1004-1010. 2012

SARMENTO, A. S. M.; BARBOSA, C.; CASTELLANI, T. T.; HANAZAKI, N. Interferência Humana no Estabelecimento e Distribuição de Furcraea foetida (L.) Haw ( Agavaceae) na Praia Mole, Ilha de Santa Catarina, Brasil: Uma Interface entre Etnobotânica e Espécies Exóticas Invasoras. Biodiversidade Brasileira, 3(2): 175-191, 2013. 
SHALLOM, D.; SHOHAM, Y. Microbial hemicellulases. Current Opinion in Microbiology, v. 6, n. 3, p. 219-228, 2003.

SHIN, K.S., LEE, Y.J. Purification and characterization of new member of the laccase family from the White - rot basidiomycete Coriolus hirsutus. Archives Biochemistry and Biophysics. 384, 109-115, 2000.

SUBRAMANIYAN, S.; PREMA, P. Biotechnology of microbial xylanases: enzymology, molecular biology, and application. Critical reviews in biotechnology, v. 22, n. 1, p. 33-64, 2002.

SUMMERELL B.A.; LESLIE J.F., Liew, E.C.Y. et al. Fungal Diversity (2011) 46: 1. https://doi.org/10.1007/s13225-010-0075-8

TAVARES, V. B., SIVIERI, K., CERON, C. R., DA SILVA, R., TRABUCO, E. Utilização de resíduo líquido de indústria de processamento de suco de laranja como meio de cultura de Penicillium citrinum: depuração biológica do resíduo e produção de enzima. Química Nova, v. 21, p.722-725, 1998.

TEETOR G.H.; Roberts D.W. 1983. Entomogenous Fusarium species. Mycopatologia 84, 316.

VALADARES F. L. Produção e uso de enzimas derivadas do fungo Pleurotus Ostreatus na hidrólise de bagaço de cana pré-tratado por processo quimiotérmico. Dissertação de mestrado, Universidade de São Paulo. Setembro de 2013.

VASQUEZ, M. P. et al. Enzymatic Hydrolysis Optimization to Ethanol Production by Simultaneous Saccharification and Fermentation. Applied Biochemistry and Biotechnology, v. 136-140, n. 2, p. 141-153, 2007.

VLEET J.H.; JEFFRIES T.W. Yeast metabolic engineering for hemicellulosic ethanol production. Department of Bacteriology, University of Wisconsin-Madison, Madison, WI 53706, United States, 2009.

VOGEL, H.J. A convenient growth medium for Neurospora (Medium N). Microbial Genet. Bull. 13, 42-43, 1956.

WANG Z., XIN H., GENG A. Cellulase production and oil palm empty fruit bunch saccharification by a new isolate of Trichoderma koningii D-64. Process Biochemistry, vol. 47, pg. 1564-1571, 2012.

WARIISHI, H., VALLI, K., GOLD, M.H. Manganese (II) oxidation by manganese peroxidase from the basidiomycete Phanerochaete chrysosporium. Journal of Biological Chemistry. 267, 23688-23695, 1992.

YOKOSUKA A., SANO T., HASHIMOTO K. Steroidal Glycosides from Furcraea foetida and Their Cytotoxic Activity. Tokyo University of Pharmacy and Life Sciences School of Pharmacy Tokyo, Japan 2009.

ZAYAS, A. A. Distribuicion geografica y possible origen de las Agavaceae. Universidad de La Habana, Revista del Jardim Botânico Nacional, 10(1): 25-36, 1989. 
GAETA, G. T. et al.

ZHU, J.Y., PAN, X.J., WANG, G.S., GLEISNER, R. Sulfite pretreatment for robust enzymatic saccharification of spruce and red pine. Bioresource Technology 100, 24112418, 2009. 